\title{
RANCANG BANGUN SISTEM UJIAN BERBASIS KOMPUTER PADA SMK BHAKTI UTAMA BANDAR LAMPUNG
}

\author{
Sidik Rahmatullah ${ }^{1}$, Kevin Aditya Pratama ${ }^{2}$ \\ Program Studi Sistem Informasi \\ STMIK DIAN CIPTA CENDIKIA KOTABUMI \\ J1.Negara No. 03 Candimas Kotabumi- Lampung Utara \\ Email: Sidik@dcc.Ac.Id, kevin@gmail.com
}

\begin{abstract}
ABSTRAK
SMK Bhakti Utama Bandar Lampung merupakan salah satu lembaga pendidikan yang beralamat di Jln. Panglima Polim No 2A, Segalamider - Bandar Lampung. SMK Bhakti Utama Bandar Lampung mempunyai tujuan untuk meningkatkan pelayananan dalam penilaian. Salah satu cara untuk mewujudkannya adalah dengan adanya suatu sistem ujian yang baik. Tapi terdapat kendala pada SMK Bhakti Utama, yaitu pengelolaan pelaksanaan ujian, penilaian dan penjadwalan, masih menggunakan cara manual dan belum terkomputerisasi, hal ini dapat menyebabkan terhambatnya proses penyampaian informasi. Oleh karena itu dilakukanlah suatu penelitian dengan tujuan untuk memperbaiki sistem yang ada di SMK Bhakti Utama Bandar Lampung dengan mengganti sistem ujian yang manual dengan yang terkomputerisasi.
\end{abstract}

Model yang digunakan adalah Model Object Oriented dengan metode pengembangan sistem waterfall. Tahapan pengembangan terdiri dari rekayasa dan pemodelan sistem informasi, analisis kebutuhan perangkat lunak, desain, pengkodean, pengujian dan pemeliharaan. Teknik pengumpulan data diantaranya yaitu metode observasi, wawancara dan studi pustaka. Sistem ini dapat melakukan pengujian siswa secara manajemen data user, menu, soal dan penjadwalan ujian.

Dengan dirancangnya sistem ujian berbasis komputer, guru dapat melaksanakan ujian dengan mudah dan langsung mengetahui hasilnya yang dapat digunakan oleh guru untuk membuat keputusan dan menyimpan berkas hasil ujian dan nilainya dengan aman dikomputer tanpa penumpukan berkas kertas hasil ujian seperti sebelumnya.

Kata kunci : Sistem Informasi, Waterfall, UBK, Ujian Berbasis Komputer, UML 


\begin{abstract}
School officials of bandar lampung is one of educational institutions jln lived at. Panglima polim no $2 a$, segalamider - bandar lampung. Vocational high schools bakti that is done routinely main bandar lampung has the goal in an attempt to improve services in the assessment of. One of the ways enough to make it is promoting the creation of a kind of a good examination systems.There are quite discernible obstacles that will emerge if on vocational high schools bakti that is done routinely main, Namely the implementation of the test management, assessment and scheduling, still use manual way and have not computerized, this may cause activities the process of the delivery of information.Hence did a research for the purpose of improving the system that is in smk bhakti main bandar lampung by replacing system test manual with computerized.

The model used is what is the model object oriented with the methods waterfall system development. Phases of the development of consisting of engineering and modeling an integrated information system for, it is anticipated that analysis the needs of software, a design, encoding, testing and maintenance of. The technique of data collection namely in a method of observation, the interviews and the literature study. Systems are believed to be do our tests student data in connection with the management user, a menu, and disputes and strife about civil servants recruitment and examination scheduling.

With dirancangnya computer based examination systems, teacher can force a class on the test they are capable of carrying portable and handy it was directly find its outcome that can be used by a tutor to make decisions and save the file the exam results to live securely in the by in terms of value dikomputer without the accumulation of file paper the exam results as you turned away before.
\end{abstract}

Keywords : information system, waterfall, ubk, the computer based, uml 


\section{Pendahuluan}

Penggunaan teknologi dalam pembelajaran sudah lama dimanfaatkan untuk membantu peningkatan kualitas pembelajaran. Pemanfaatan teknologi dalam proses pembelajaran terutama teknologi komputer memudahkan para pendidik. Untuk menjelaskan materi pembelajaran yang bersifat abstrak dan jauh dari penalaran peserta didik menjadi mudah dijangkau atau dipahami. Melalui teknologi pembelajaran para pendidik akan mudah melakukan simulasi pembelajaran mendekati kondisi nyata dari suatu materi pembelajaranyang abstrak, seperti dengan animasi, tutorial, atau demo visualisasi lainnya sehingga akan memudahkan pemahaman dan penghayatan peserta didik untuk materi yang diajarkan.

Ujian merupakan salah satu kegiatan pelaksanaan kurikulum yang tidak dapat dipisahkan satu dengan kegiatan lainnya. Berhasil atau tidaknya pelaksanaan kurikulum dapat dilihat dari keberhasilan ujian dalam arti sesungguhnya. Keberhasilan ujian tidak cukup dilihat dari segi keberhasilan para siswa dalam memperoleh nilai yang baik serta mutu para siswa itu sendiri, tetapi juga dilihat dari segi teknis pelaksanaan ujian. Kemajuan dan keberhasilan materi tersampaikan dapat dilihat dari kelulusan siswa pada ujian di materi tersebut. Soal ujian dimaksudkan untuk memantau mutu pendidikan dan mengetahui kemampuan yang dimiliki siswa sesuai dengan muatan materi dari kurikulum yang dipakai oleh guru.

Pelaksanaan ujian pada umumnya membutuhkan kertas yang digandakan untuk soal dan lembar jawaban, audit penilaian yang dilakukan secara manual oleh guru, sehingga pengaplikasian pelaksanaan ujian berproses lama dan memakan biaya.

Pelaksanaan ujian di SMK Bhakti Utama Bandar Lampung, baik ujian harian, tengah semester maupun ujian sekolah (soal dibuat sendiri oleh sekolah, bukan dari MGMP maupun Dinas Pendidikan) masih menggunakan metode konvesional yang memerlukan waktu, biaya dan tenaga yang cukup banyak. Kegiatan ujian harian biasanya diawali dari pembuatan soal dari guru bidang studi, soal yang dibuat oleh guru akan digandakan pihak akademis. Kemudian untuk mengtahui hasilnya, lembar jawaban siswa dikumpulkan dan dikoreksi oleh guru bidang studi. Siswa juga tidak dapat langsung mengetahui hasil ujian atau nilanya.

Sistem ujian konvensional yang sering dipakai dalam kegiatan akademik sering kali mempunyai banyak kendala. Faktor kecurangan dan kebiasaan mencontek merupakan kendala yang paling besar. Selain itu faktor lambatnya proses penilaian dalam ujian konvensional atau tertulis dikarenakan pesertanya yang banyak sehingga dapat menghambat guru dalam memasukkan nilai kedalam raport. Pemborosan biaya kertas dan tinta dalam pembuatan soal dan penggandaan soal 
termasuk kedalam faktor negatif dalam ujian konvesional. Setelah diketahui, jumlah siswa pada SMK Bhakti Utama 287 dibagi dalam beberapa kelas yang akan disimpulkan akan lama prosesnya dalam pengoreksian jawaban dan mengolahnya.

Banyak pengertian sistem yang diungkapkan oleh beberapa pakar manajemen yang dijelaskan dari berbagai sudut pandang yang berbeda, namun mempunyai tujuan yang sama. Pengertian sistem adalah kumpulan atau group dari sub sistem atau bagian atau komponen apapun baik fisik maupun non fisik yang saling berhubungan satu sama lain dan bekerja sama secara harmonis untuk mencapai satu tujuan tertentu.

Informasi merupakan hasil dari data yang di proses yang berasal dari inputan suatu kejadian yang nyata yang berguna bagi pemakainya. Pengertian informasi diatas merupakan pengembangan teori yang di kemukakan oleh Jogiyanto (2005:8) yang menyatakan bawah informasi adalah data yang di olah menjadi bentuk yang lebih berguna dan lebih berarti bagi yang menerimanya.

Menurut Ladjamudin (2007), sistem adalah sekelompok bagian-bagian (alat dan sebagainya) yang bekerja bersamasama untuk melakukan suatu maksud. Suatusistem adalah jaringan kerja dari prosedur-prosedur yang saling berhubungan, berkumpul bersama-sama untuk melakukan suatu kegiatan atau menyelesaikan suatu sasaran tertentu.
Informasi adalah data atau fakta-fakta yang telah diproses sedemikian rupa sehingga berubah bentuknya menjadi informasi

Hoga Saragih (2014) dalam penelitiannya yang berjudul "Analisis Kualitas Aplikasi Ujian Online Berbasis Web Pada Perum Perumnas" yang berkesimpulan bahwa hasil analisis aplikasi ujian online dengan aplikasiWeb-QEM (Website Quality Evaluation Method). Persamaan penelitian dengan penelitian terdahulu adalah membahas tentang ujian online atau ujian berbasis komputer, sedangkan perbedaanya adalah bahwa peneliti terdahulu hanya melakukan analisa terhadap aplikasi ujian online yang berjalan, namun saya ingin merancang bangun sistem ujian berbasis komputer.

Roger Pakpahan (2016) dalam penelitiannya yang berjudul "Model Ujian Nasional Berbasis Komputer: Manfaat dan Tantangan" yang berkesimpulan bahwa penelitiannya adalah menjelaskan manfaat dan tantangan dalam pelaksanan ujian berbasis komputer. Persamaan penelitian ini dengan penelitian terdahulu adalah membahas tentang ujian berbasis komputer, sedangkan perbedaannya adalah bahwa peneliti terdahulu hanya memaparkan manfaat dan tantangan dari ujian berbasis komputer, namun saya ingin membuat aplikasi sistem ujian berbasis komputer. 


\section{MetodePenelitian}

Ada tiga metode pengumpulan data yang penulis gunakan yaitu :

a Metode Observasi, tahap ini adalah melihat kegiatan ujian pelajaran KKPI di SMK Bhakti utama Bandar Lampung

b. Metode Wawancara,yaitu dengan tanya jawab kepada Guru KKPI yang ada di SMK Bhakti Utama terkait :

- Kurikulum yang dipakai serta muatannya

- Sistem ujian dan pelaksanaannya

- Sistem penilaian dan rencana tindak lanjut

c. Metode Studi Pustaka, tahap ini adalah kegiatan yang dilakukan yang dilakukan penulis dengan cara mencari bahan yang mendukung dalam pendefenisian permasalahan melalui buku-buku, internet, yang erat kaitannya dengan objek permasalahan diatas.

Adapun metodologi penelitian yang digunakan dalam penelitian ini adalah menggunakan metode pengembangan sistemwaterfall dengan tahapannya adalah sebagai berikut :

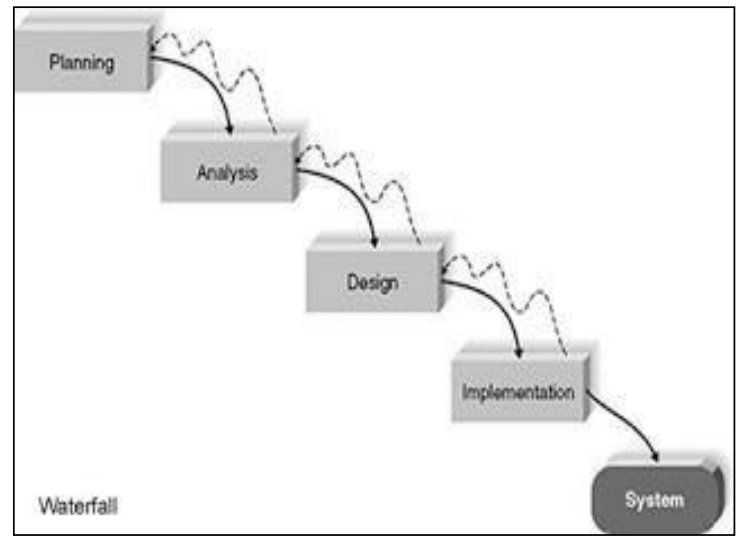

Gambar 1 MetodePengembangansistem waterfall

\section{SkemaTeknologiJaringan}

Jaringan komputer berupa LAN (Local Area Network) dengan switch/hub serta kabel UTP sebagai pendukung topologi jaringan yang digunakan. Berikut adalah gambar untuk organisasi jaringan komputer sistem yang diusulkan.

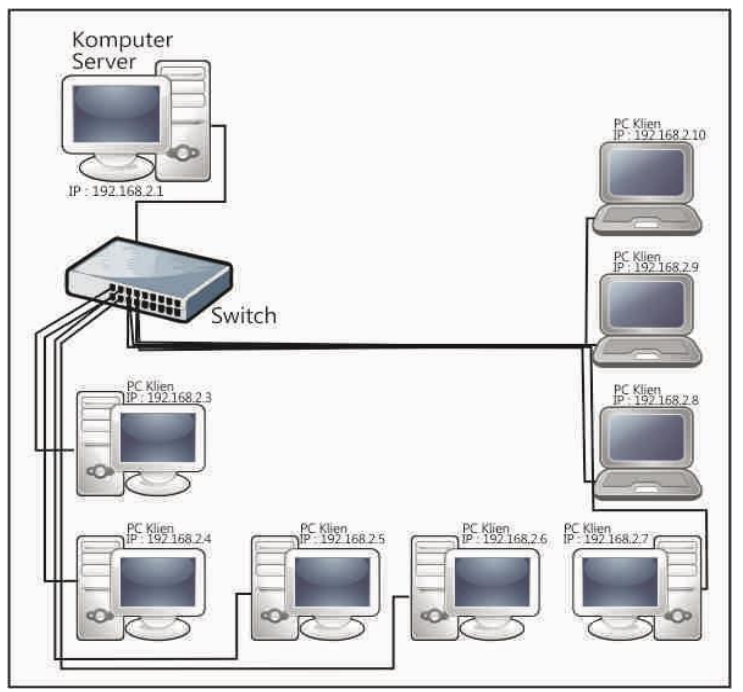


Gambar2 SkemaTeknologiJaringan

\section{HasildanPembahasan}

Pada pembahasan hasil program ini dijelaskan dalam bentuk tampilan program yang telah dijalankan (running). Penjelasan ini bertujuan untuk memperlihatkan hasil desain dari bab sebelumnya. Tampilan program dan penjelasan fungsi atau kegunaan tomboltombol yang terdapat pada program aplikasi ini adalah sebagai berikut:

\subsection{Form Login}

Form login merupakan login yang akan dilakukan oleh admin, guru dan siswa sebagai hak akses mereka untuk masuk kedalam sistem dan mendapatkan fungsi dari sistem ini masing-masing. Berikut adalah tampilan dari form login.

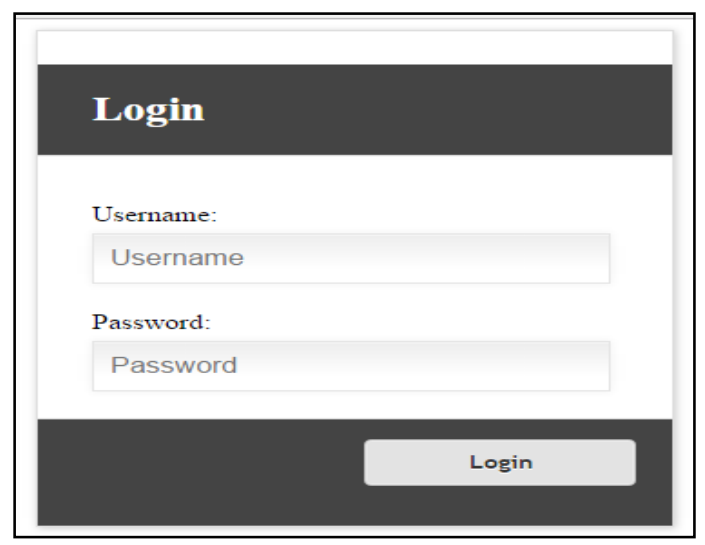

Gambar 3 Form Login

\subsection{Menu Beranda Administrator}

Halaman ini hanya berisi ucapan selamat datang, menunjukkan hari, tanggal dan waktu, serta slide gambar yang membuat tampilan lebih menarik

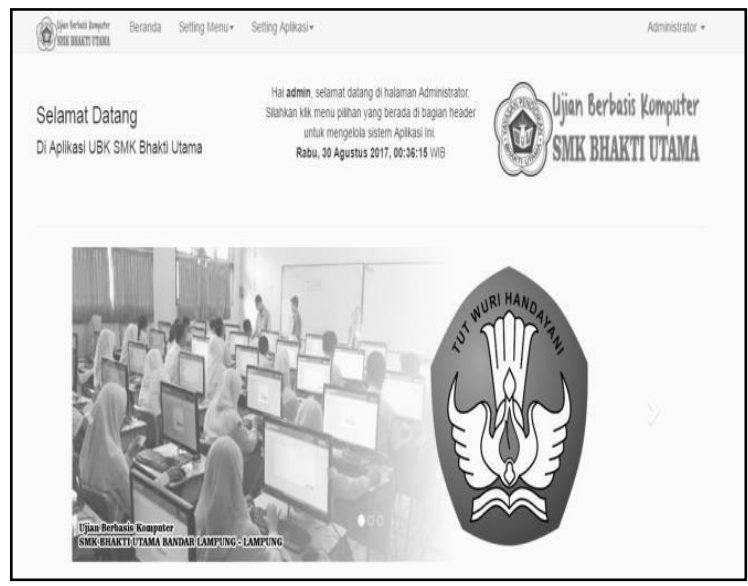

Gambar 4Menu Beranda Administrator

\subsection{Setting MenuAdministrator}

Halaman ini berisi pengaturan untuk semua menu yang dapat diakses di semua user, baik admin, guru dan siswa.

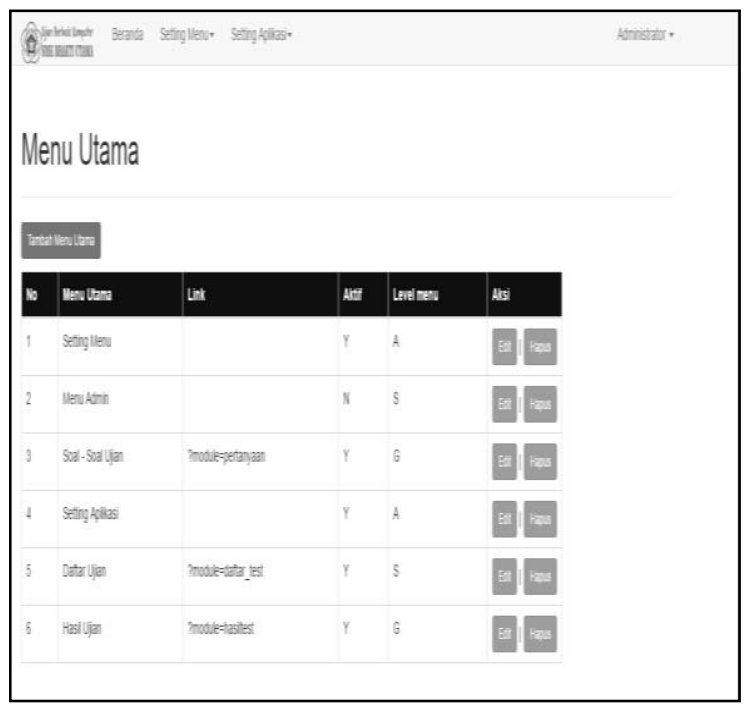

Gambar 5 Setting Menu Administrator 


\subsection{HalamanKategoriUjian}

Halaman ini berisi pengaturan kategori ujian. Kategori dapat ditambah dan diaktifkan ketika akan dilaksanakan ujian tersebut. Namun kategori tidak dapat dihapus.

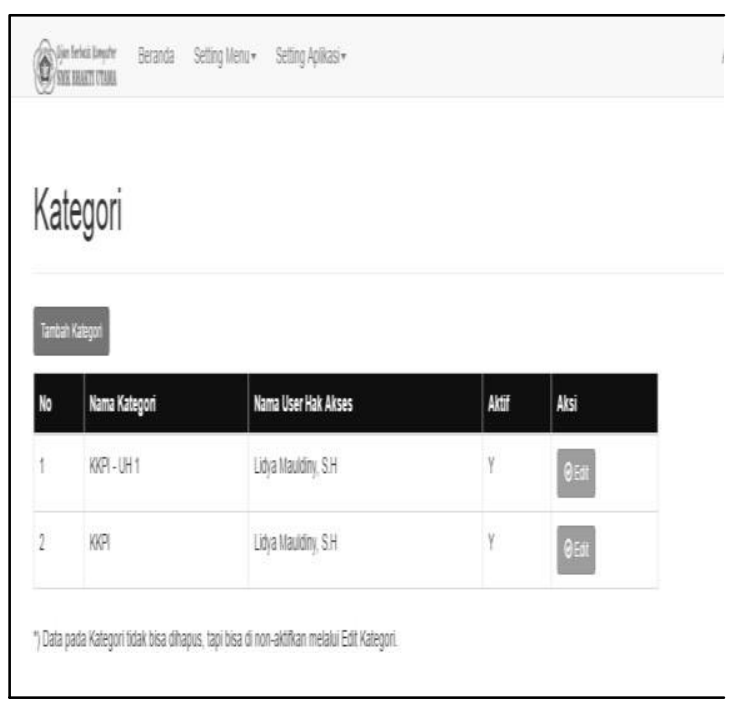

Gambar 6Halamankategoriujian

\subsection{Halaman Edit Kategori}

Halaman ini berisi pengubahan kategori jika ada kesalahan dan aktifkan kategori.

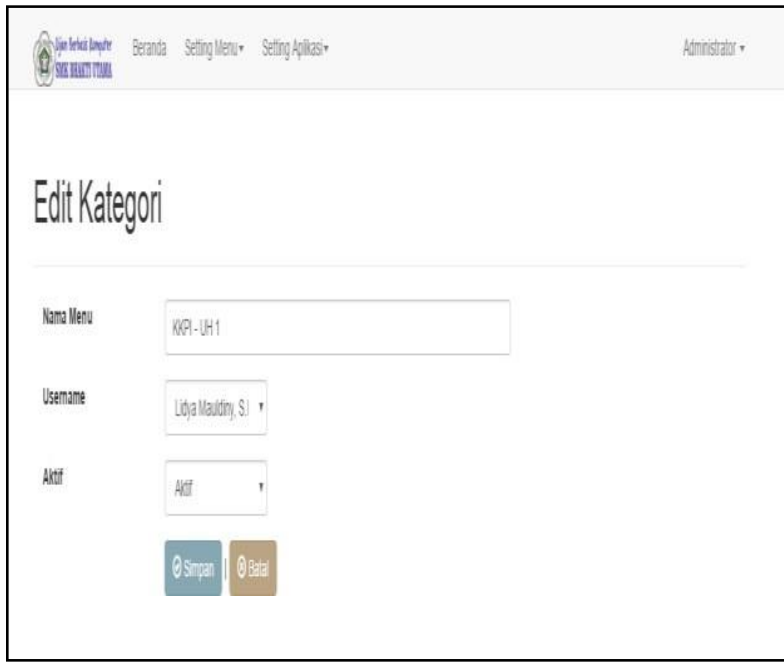

Gambar 7Halamaneditkategori

\subsection{Halaman Reset Aplikasi}

Halaman ini berisi reset atau kembali ke pengaturan awal ketika aplikasi dibuat. Akan menghapus semua data yang ada, seperti soal dan jawaban siswa yang pernah diujikan.

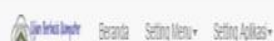

A

Resethpi|kasi

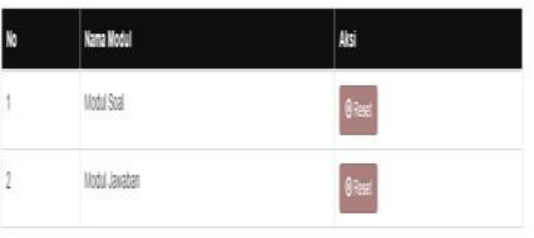

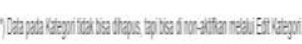

Gambar8 Reset Aplikasi 


\subsection{Halaman Kelola User}

Halaman ini berisi semua user yang dapat menggunakan aplikasi ini, baik admin, guru dan siswa. Berfungsi untuk menambahkan user dan mengubah data. Data yang diperlukan yaitu nama lengkap, username, password, email, jabatan (admin, guru mata pelajaran, dan siswa kelas berapa).

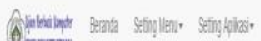

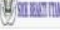

\section{Setting User Admini, Guru dan Siswa}

\section{Berile}

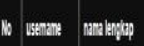

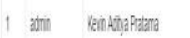

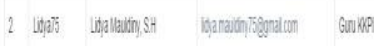

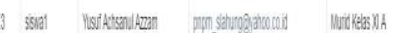

Gambar 9Halamankelola user

\subsection{Halaman Beranda Guru}

Halaman ini hanya berisi ucapan selamat datang, menunjukkan hari, tanggal dan waktu, serta slide gambar yang membuat tampilan lebih menarik.

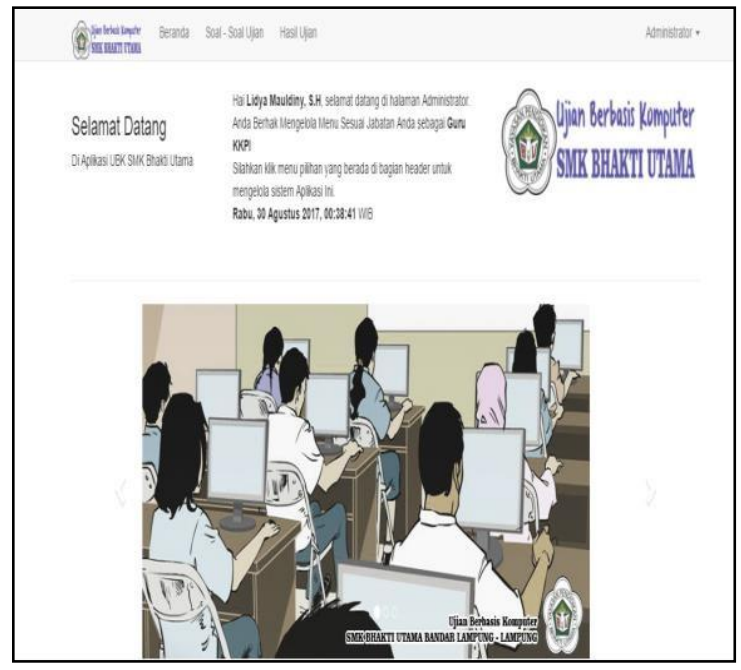

Gambar 10Halamanberanda guru

\subsection{HalamanSoal}

Halaman ini berisi soal yang ada pada kategori ujian yang dapat dikelola oleh guru. Terdapat fitur tambah soal atau import menggunakan excel.

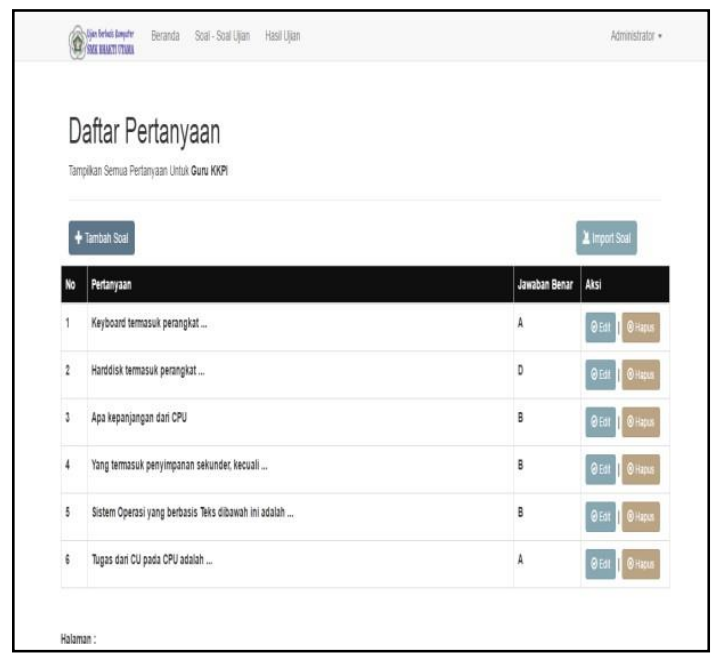


Gambar11HalamanSoal

\subsection{Halaman Input Soal}

Halaman ini adalah halaman untuk menambahkan soal. Terdiri dari pilihan jawaban dan jawaban benar

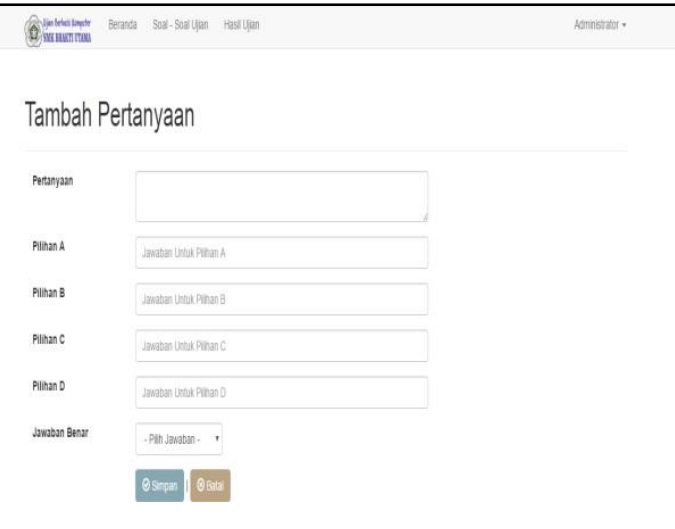

Gambar 12Halaman Input Soal

\subsection{Halaman Hasil Ujian}

Halaman ini adalah halaman yang dapat dikelola guru, berisi rekap jawaban dan nilai yang siswa yang telah mengikuti ujian

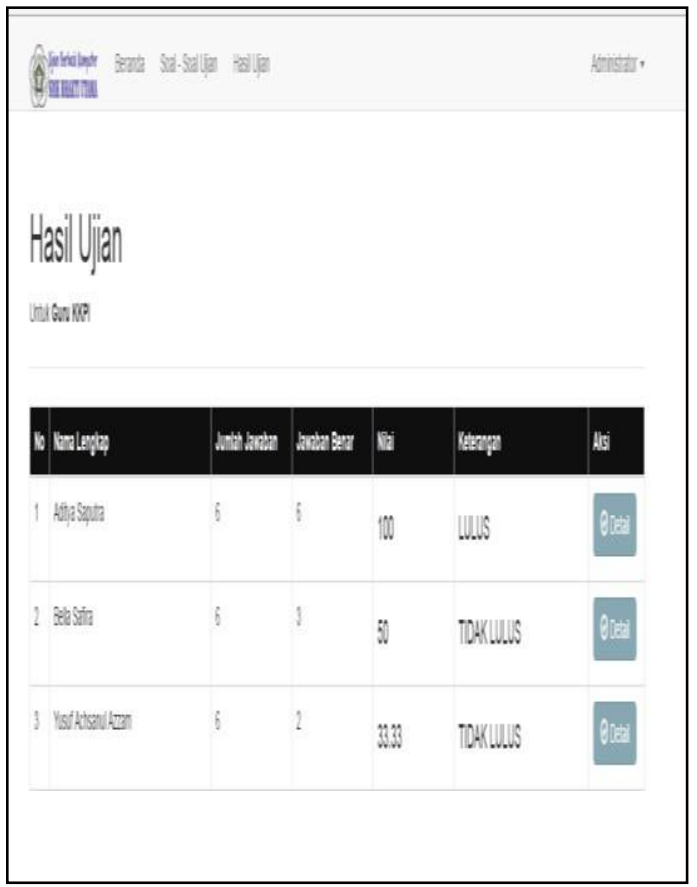

Gambar 13 HalamanHasilUjian

\subsection{Halaman Detail Hasil Ujian}

Halaman yang masih dikelola oleh guru, berisi rekapan detail jawaban siswa.

\begin{tabular}{|c|c|c|}
\hline 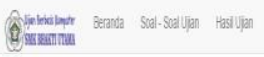 & & knisistat \\
\hline Detail Hasil Ujälan & & \\
\hline Ho Prtaysan & Janban Restat & sambenenar \\
\hline 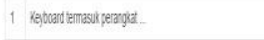 & A & A \\
\hline 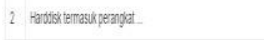 & $c$ & 0 \\
\hline 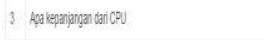 & 8 & 8 \\
\hline 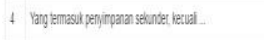 & 0 & $B$ \\
\hline 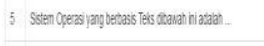 & A & B \\
\hline 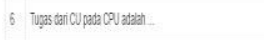 & 0 & A \\
\hline Benar:2 Salah: 4 & & \\
\hline
\end{tabular}


Gambar 13 Halaman Detail HasilUjian

\subsection{Halaman Beranda Siswa}

Halaman ini hanya berisi ucapan selamat datang, menunjukkan hari, tanggal dan waktu, serta slide gambar yang membuat tampilan lebih menarik.

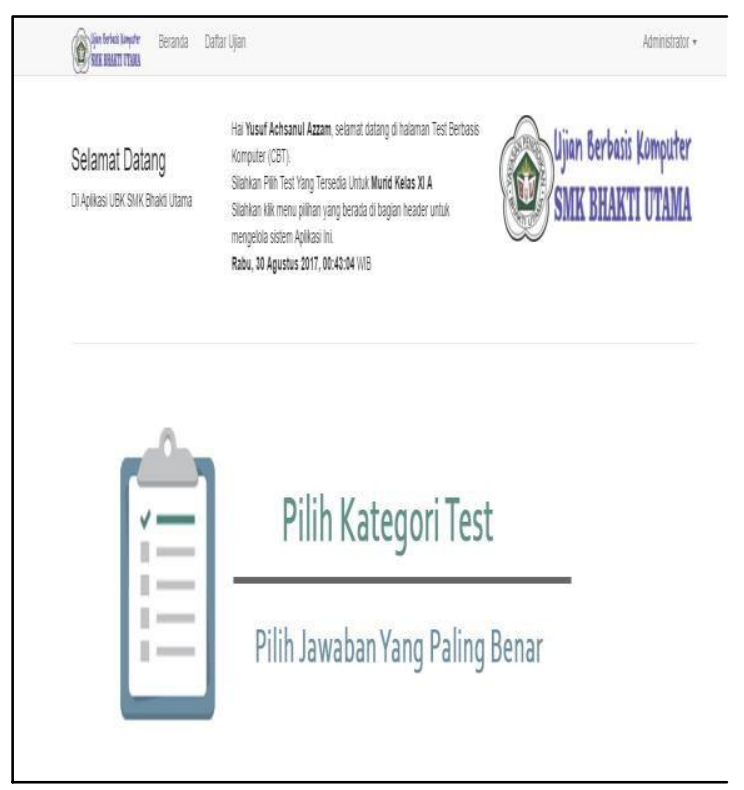

Gambar 14HalamanBerandaSiswa

\subsection{Halaman Daftar Ujian}

Halaman yang dikelola siswa berupa daftar ujian dari kategori ujian yang aktif

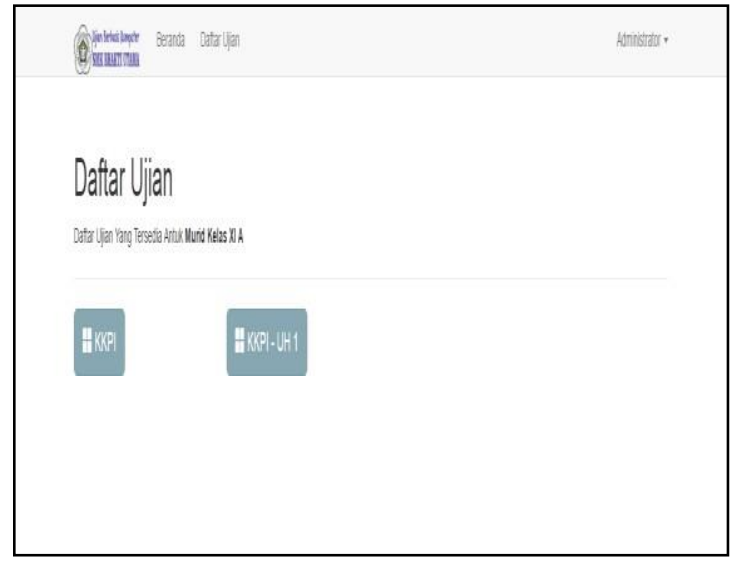

Gambar 15HalamanDaftarUjian

\subsection{Halaman Mengerjakan Ujian}

Halaman ini berisi daftar soal yang akandikerjakanoleh siswa

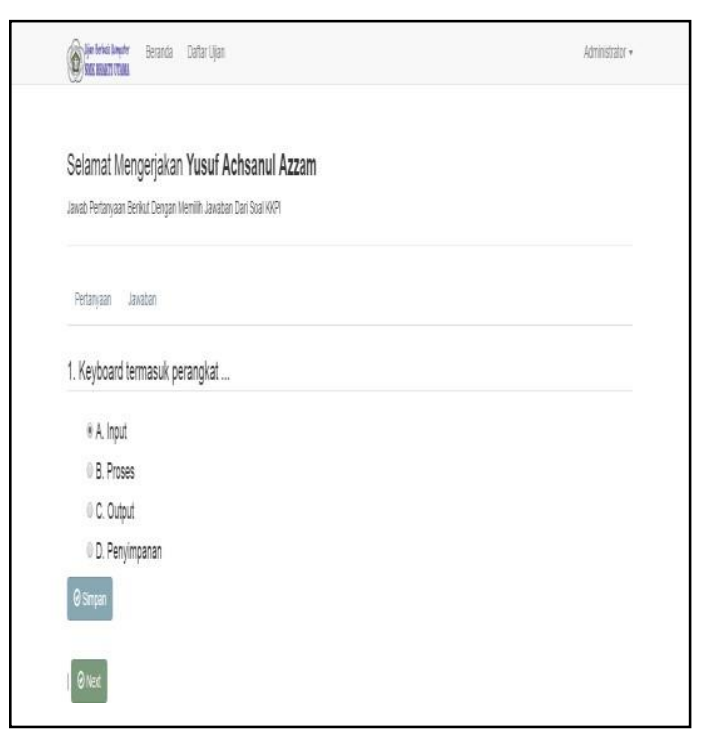

Gambar16 Halamanmengerjakanujian 


\subsection{Halaman Rekap Jawaban Siswa}

Halaman ini adalah rekapan jawaban yang dikerjakan oleh siswa ketika siswa tersebut mengerjakan. Berbeda dari halaman rekapan yang di halaman guru.

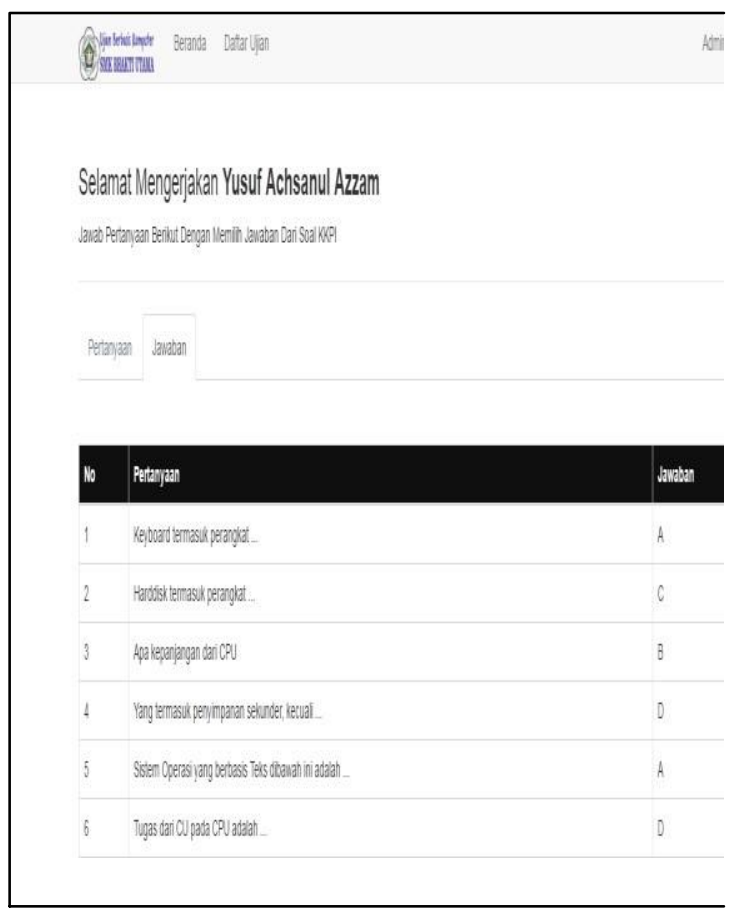

Gambar 17 HalamanRekapJawabanSiswa

\section{Kesimpulan}

Berdasarkan hasil penelitian dan pembahasan yang telah dilakukan, maka didapatkan kesimpulan bahwa :

1. Aplikasi yang dibuat adalah perangkat ujian online dengan kemampuan sistem menganalisa hasil ujian siswa yang membantu guru menentukan siswa yang belum mampu dalam sebuah mata pelajaran.
2. Terciptanya proses ujian yang berlangsung lebih cepat dan efisien karena tidak memerlukan media alat tulis seperti ujian konvensional dan memudahkan guru karena tidak perlu melakukan pengecekan jawaban siswa dan langsung mengetahui nilai mereka karena nilai akan muncul secara realtime

3. Ketika diimplementasikan untuk ujian dapat mempemudah siswa dalam pelaksanaan ujian dan guru dalam melaksanakan penilaian. Sehingga secara garis besar, sistem ini dapat membantu dan meningkatkan kinerja guru dalam proses penilaian dan pembuatan soal

\section{Saran}

Untuk pengembangan lebih lanjut untuk sistem ini, ada beberapa saran yang dapat diberikan, antara lain :

1. Aplikasi diupload di internet atau domain public agar dapat diakses dimana dan kapan saja sebagai latihan bagi siswa dalam mengevaluasi kemampuan mereka.

2. Kurangnya menu untuk mengacak soal maka ditambahkan pengaturan menu untuk pengacakan soal dan fitur unduh soal agar setelah ujian siswa dapat mengunduh soal dalam bentuk pdf sebagai latihan dan arsip soal mereka. 
3. Untuk ujian skala lokal atau masih dengan local area network (LAN) dapat dikembangkan dengan menggunakan remote desktop agar pengawas bisa langsung mengawasi proses ujian secara langsung dari monitor pengawas.

\section{DaftarPustaka}

Kadir, Abdul. 2014. Pengenalan Sistem Informasi Edisi Revisi. Andi. Yogyakarta.

Jogiyanto. 2005. Analisis dan desain sistem informasi. Andi Offset. Yogyakarta

Hariyanto, Agus. 2017. Membuat aplikasi Computer Best Test dengan PHP MySQLi \& Bootstrap. Lokomedia. Yogyakarta.

Oetomo, Budi Sutedjo Dharma. 2007. Pengantar Teknologi Informasi Internet Konsep dan Aplikasi. Penerbit Andi. Yogyakarta.

Hariyanto, Bambang. 2004. Rekayasa sistem Berorientasi Objek. Informatika Bandung. Bandung.

Pressman, Roger R. 2012. Rekayasa Perangkat Lunak. Andi. Yogyakarta

Kemdikbud. 2017. UBK. Diakses dari http://ubk.kemdikbud.go.id/tentang.

Tim Bootstrap. 2017. Bootstrap. Diakses dari : http://getbootstrap.com/getting started.

Hoga Saragih, Siti Safariana, 2014, Analisis Kualitas Aplikasi Ujian Online Berbasis Web Pada Perum Perumnas, JurnalSistemInformasi (Journal of Information Systems).2/10 (2014),63-69
Rogers Pakpahan, 2016, Model Ujian Nasional Berbasis Komputer: Manfaat dan Tantangan, JurnalPendidikandanKebudayaan, Vol. 1, Nomor 1, April 2016. 
ISSN :2337-8344

70

Jurnal Informasi Dan Komputer 